\title{
CORRELATION BETWEEN SOLAR CYCLES AND DUST ACTIVITY OVER IRAQ
}

\author{
Bashair Abdul-Rahaman Mohammed \\ College of Science, University of Baghdad.
}

\begin{abstract}
This work presents the results of statistical analysis of observed and severe dust visibility in Iraq in relation to the sunspot cycle for the periods 1959-2007 for Baghdad, 1978-2001 for Rutbah and 1987-2007 for Mousl, Nasiriyah and Basrah. Examination of each dust series was subjected to time and spectral analysis based on lag correlation. The result shows presence of a significant dust cycle similar to the sunspot cycle. The cross-correlation between the dust and air temperature with the sunspot activity shows a high correlation with the 11year sunspot cycle. Moreover, Fast Fourier Transformation spectral analysis for the dust series confirms the similarity agreement to the sunspot variations.
\end{abstract}

\section{Introduction}

For many years efforts have been exerted to describe relationships between climate and solar activity. Many researchers have examined various types of meteorological data looking for evidence of a relationship with the 11 year sunspot cycle. The close connection between sunspots, cloudiness and rainfall were observed from 1908 at Blue Hill observatory. The relationships were found in the same cycle tendency and a significant correlation between these parameters was found (Palmer, 1910) [1]. Willett (1965) [2] argued that a 5.5 year half cycle and 22 year double cycle occurred within the pattern of the general circulation of the atmosphere. Gerety et al. (1977) [3] conducted an exhaustive cross-spectral analysis of the single and double sunspot cycles in temperature and precipitation data from approximately 300 unevenly spaced stations around the world. Annual and seasonal analyses were performed to investigate evidence for a solar signal in either temperature or precipitation. They have found no linear correlation between sunspots and seasonal temperature and precipitation. Hancock et al. (1979) [4] performed similar cross-spectral analyses. Their results showed several instances in which a solar-weather relationship could be established. Goudie et al. (1992) [5] studied the changing frequency of dust storms by analyzing long-term meteorological records. The study concluded that there is no global pattern in the frequency of dust storms. Qian et al. (2002) [6] investigated the variation of dust storms and its climatic control in China. Their results showed that there is inter-annual variability and a long-term trend between the frequency of dust-casuing weather and air temperature in northern China. Ananthakrishnan et al. (2003) [7] presented a detailed study of the annual rainfall at India in relation to sunspot cycles for the period 1871 to 1978 . The correlation coefficient for the full period of 306 stations showed a significant relationship. Gleisnaer et al. (2003) [8] studied the climate responses to the 11 year solar cycle based on NCEP/NCAR (National Center for Atmospheric Research/ National Center for Environmental Prediction) reanalysis data set. Their results showed statistical evidence for significant positive response of the troposphere temperature to the 11 year solar cycle. Boberg et al. (2005) [9] reviewed the influence of solar activity on Earth's climate. Their study concluded that the controversy surrounding many proposed solar-weather relationships originates in the lack of accepted physical mechanisms linking solar variability to climate change. In Iraq, many researchers are trying to characterize and quantify the effect of dust and dust storms on different aspects. A recent paper by Mohammed (2009) [10] draws attention to the relation between the solar cycle and dust storm variability in Iraq.

In this paper, 50-years of data from Baghdad and 25-30-years of data from four additional meteorological stations distributed around the country are used to examine possible effect of the 11- year sunspot cycle on 
the dust storms activity. The relation between air temperature at Baghdad station and the 11year sunspot cycle is also studied using autocorrelation, cross-correlation and spectral analysis.

\section{Meteorological Data}

The study was undertaken for five meteorological stations distributed over Iraq, two in the south (Basrah and Nasiriyah), one in the west (Rutbah), one in the middle (Baghdad) and one in the north (Mosul) (Fig.(1)). The data covered the periods (19592007) for Baghdad, (1978-2001) for Rutbah, and (1978-2007) for the other stations.

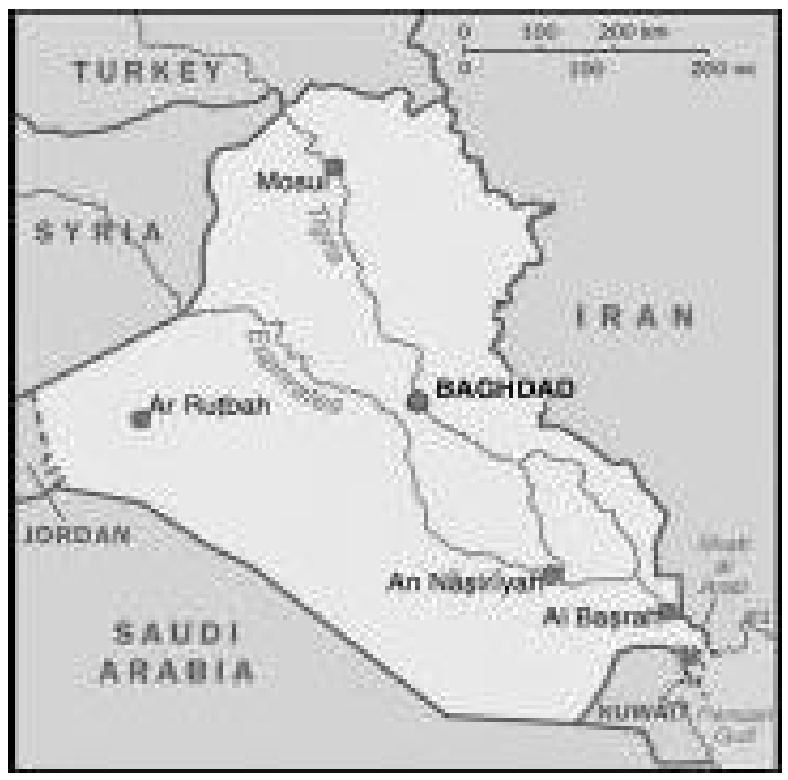

Fig.(1) : Location of the five meteorological stations.

The collected data were categorized according to the dust behavior as rising, suspended and dust storm, and characterized according to visibility, as severe dust with visibility less than $1 \mathrm{~km}$ and observed dust of less than $8 \mathrm{~km}$. Statistical polynomial interpolation were used to treat the short breakout period of the war (2001-2004), while the data smoothed by three moving points average method. The visibility was measured for every three hours intervals (observation) using visual contrast method. It may be useful to mention that the accuracy of the measurements is dependent on observer's estimation and the human made error was expected, especially during night conditions.

It's noticed that these errors don't affect the general trend of the distribution. The dust distribution for each station is plotted in Fig.(2). It is clearly shown that the observed and severe dust cycles vary according to the sunspot cycle [11].

In addition, it is noticed that $50 \%$ of the severe storms have visibilities of less than $500 \mathrm{~m}$ at Baghdad, Basrah and Nasiriyah, while it is unusual to find severe storms at Mosul and Rutbah. By comparing the dust activities from the five stations, it is clear that the number of observed dust storms is higher at the stations in the middle and southern part of Iraq (i.e. Nasiriyah, Basrah, and Baghdad) and lower in the other stations (e.g. Mosul and Rutbah). It appears that the stations with higher dust activity are located closer to the desert while the stations with lower dust activity are located away from the desert. It is also noted that the number of storms at Nasiriyah occurs at the order of seven times more than storms in Baghdad and twenty times more than storms in Mosul, which means lowest effects were expected in the north.
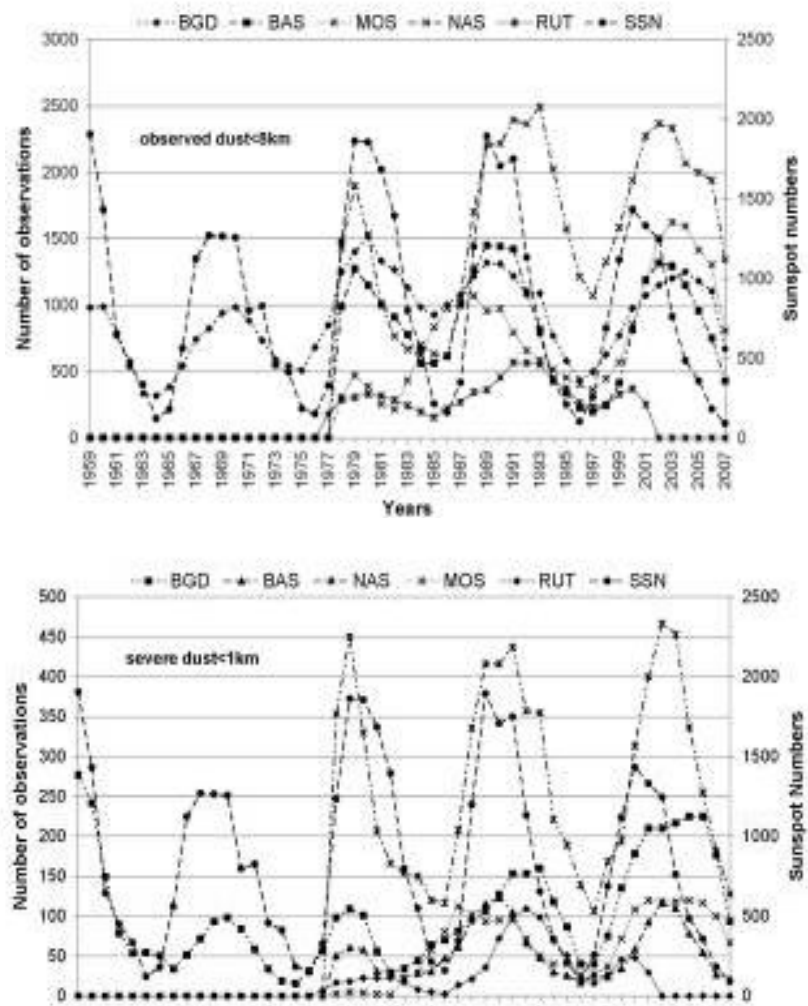

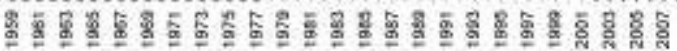
Years

Fig.(2): Dust distribution for the five stations compared to the sunspot cycles.

"BGD, BAS, NAS, MOS, RUT and SSN are abbreviations for Baghdad, Basrah, Nasiriyah, Mousl Rutbah and Sunspot number". 


\section{Dust and Sunspot Cycles}

\section{Auto-correlation}

When the correlation calculated between a series and a lagged version of itself, this will be called autocorrelation. A high correlation is likely to indicate a periodicity in the signal of the corresponding time duration (Davis J.C 1986) [12]. The sunspot cycle period occurs within the pattern of 11 years. The 5.5 year half cycle and the 22 year double cycle were also observed. The dust series variation is tested for each station to explore its periodicity cycle. Fig.(3) presents the autocorrelation for the observed dust and severe dust storms. It shows that the variability of the dust cycle has significant similarity with the sunspot cycle for all stations. The results also show that the data series recorded at the southern and middle stations (Nasiriyah, Basrah and Baghdad)
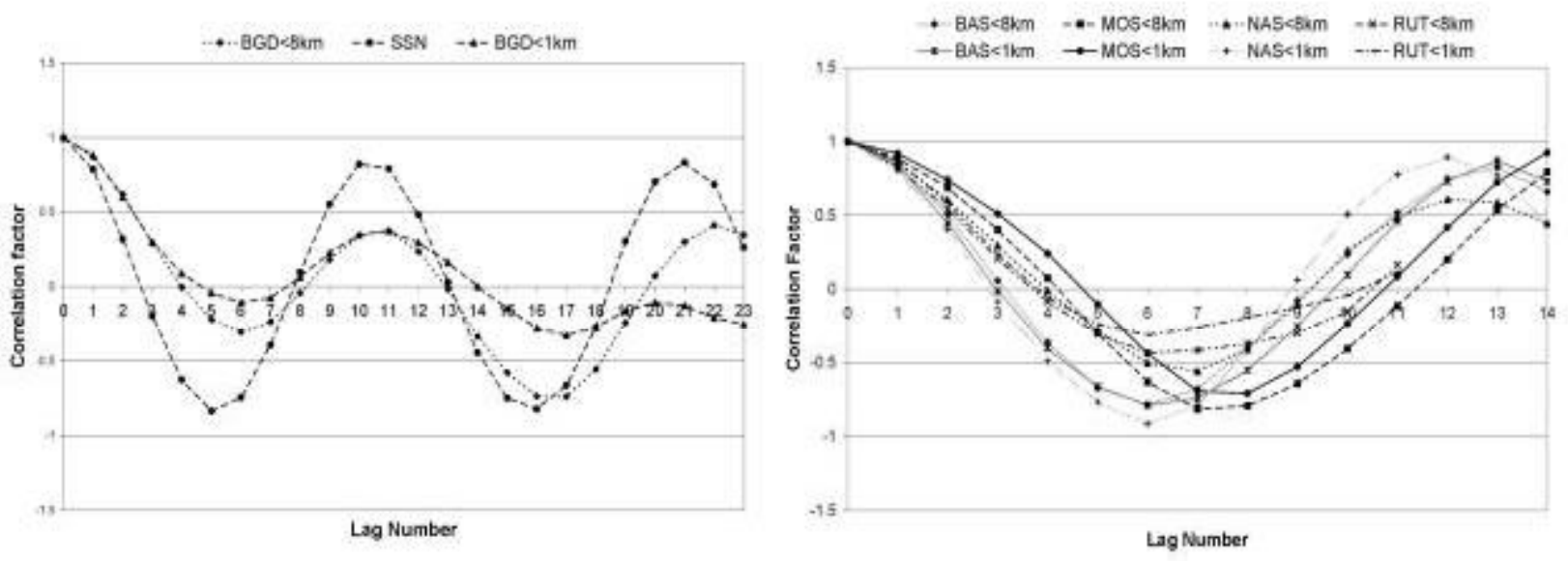

Fig.(3) : Autocorrelation for the observed and severe dust for the five stations.
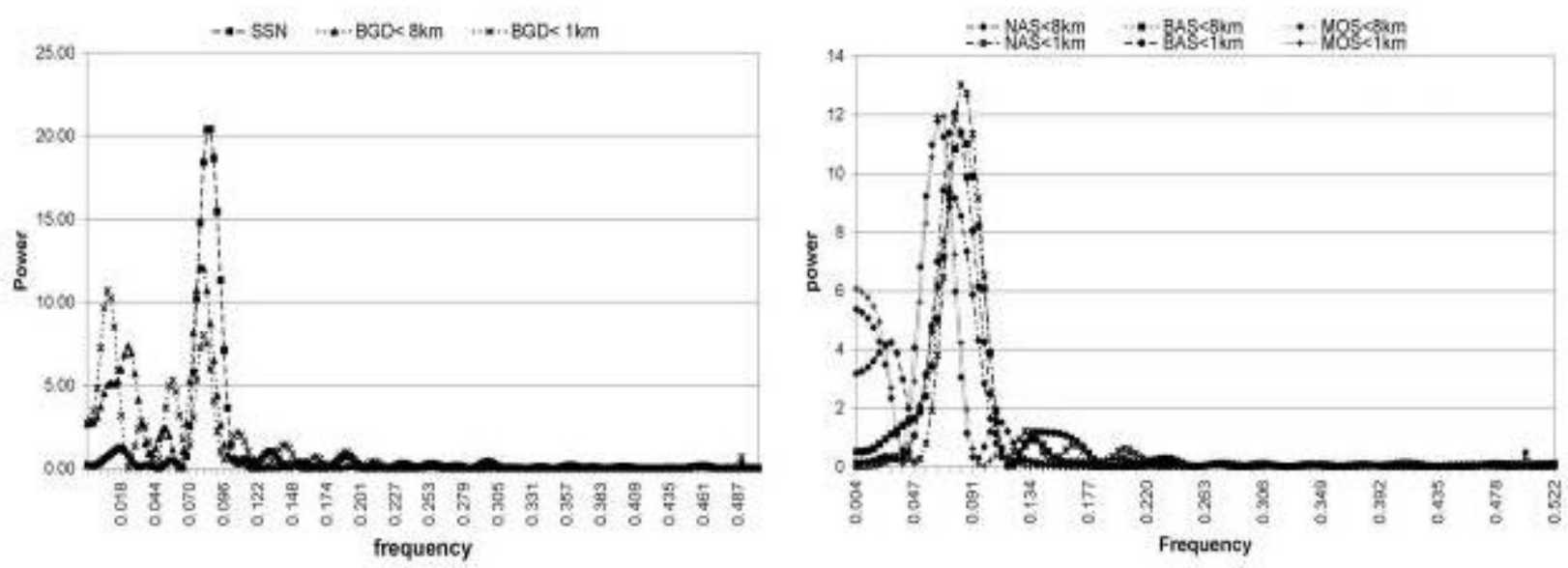

Fig.(4) : Spectral analysis for the observed and severe dust series. 


\section{Cross-Correlation}

Cross-correlation is a standard time analysis method of estimating the degree of correlation between two data series. The cross correlation between the sunspot cycle and each of the data series for the observed dust and the severe dust are presented in Fig.(5). It is clear to show the presence of correlation between the dust cycle with the sunspot cycle and the highest correlations appears at lags of 11 years. A high degree of correlations were noticed in the middle and southern parts of the country while the correlation
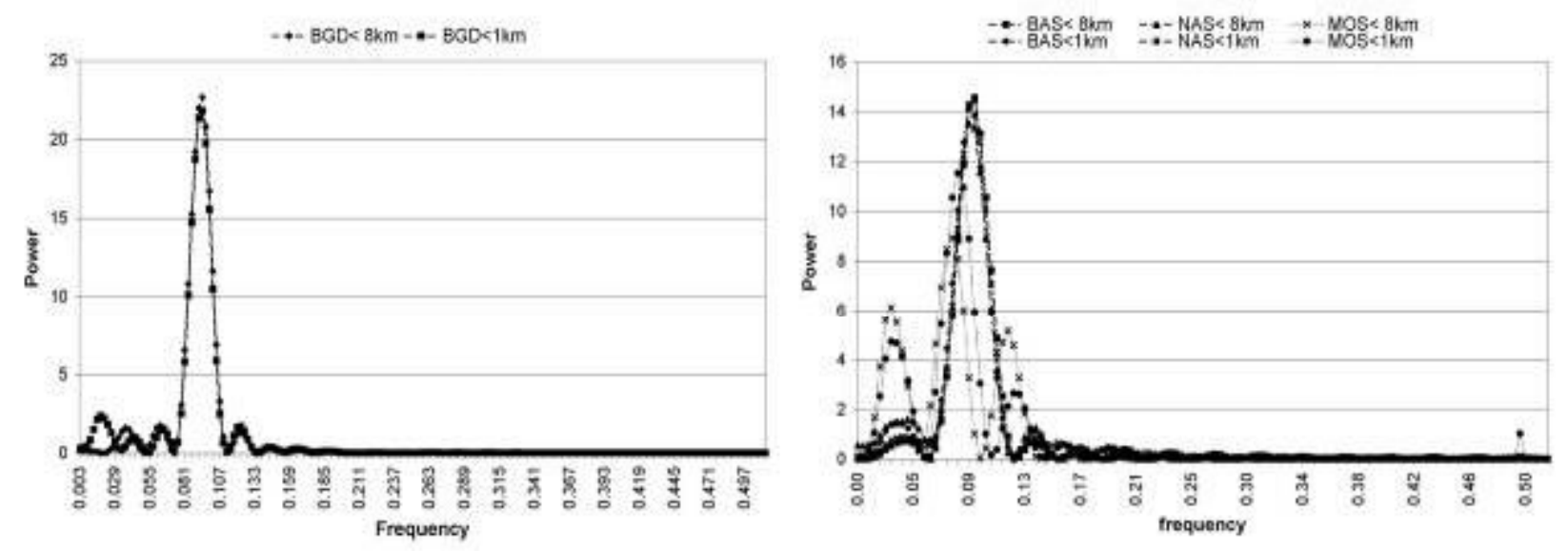

Fig.(5) : Cross-correlation between the observed and sever dust with the sunspot cycles.
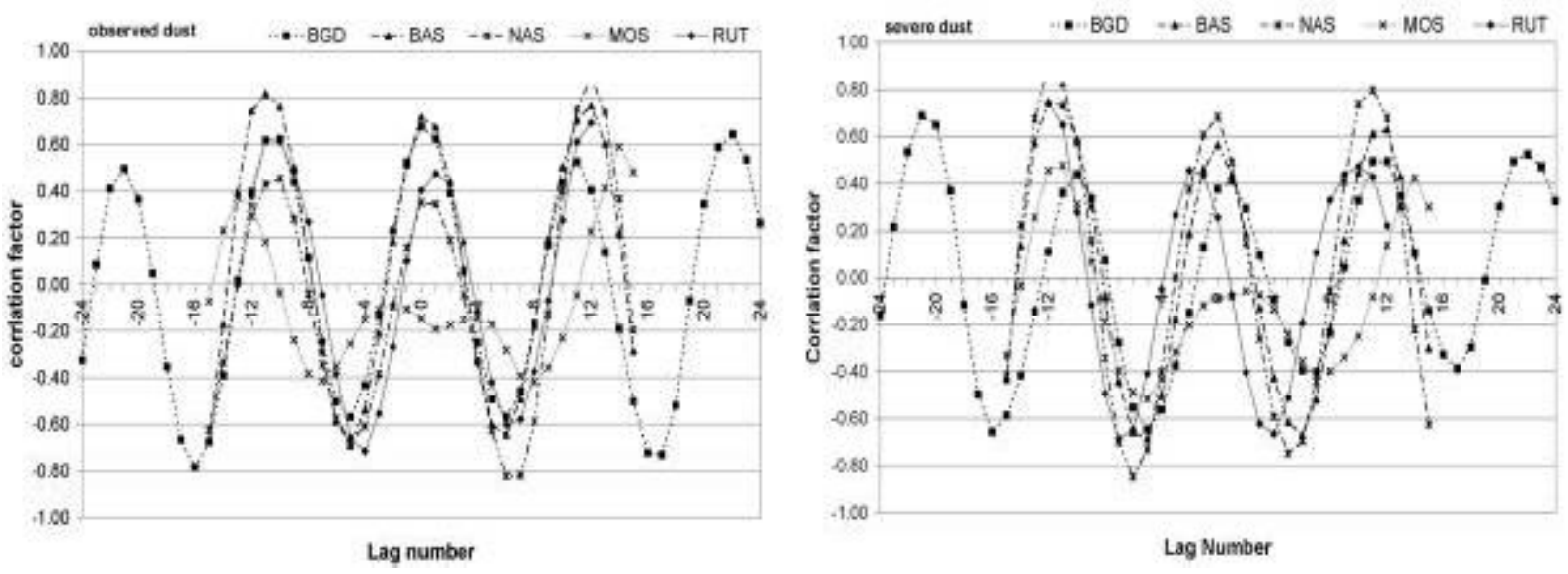

Fig.(6) : Spectral analysis for the correlated data series. 


\section{Weather parameters}

Other weather parameters [13] were also tested to investigate its relation to the sunspot cycle. The results show significant presence of positive correlation with air temperature and wind speed while negative correlation found to the rain rate and humidity. Fig.(7) presents the mean air temperature cycle compared and correlated to the sunspot and observed dust cycles at Baghdad. It is clear to show the positive correlation between the three parameters. The FFT spectral analysis shows positive correlation between temperature-dust and temperature-sunspot cycle with frequency in the order of 0.096 Cycle/year (10.5 years) as in Fig.(8).
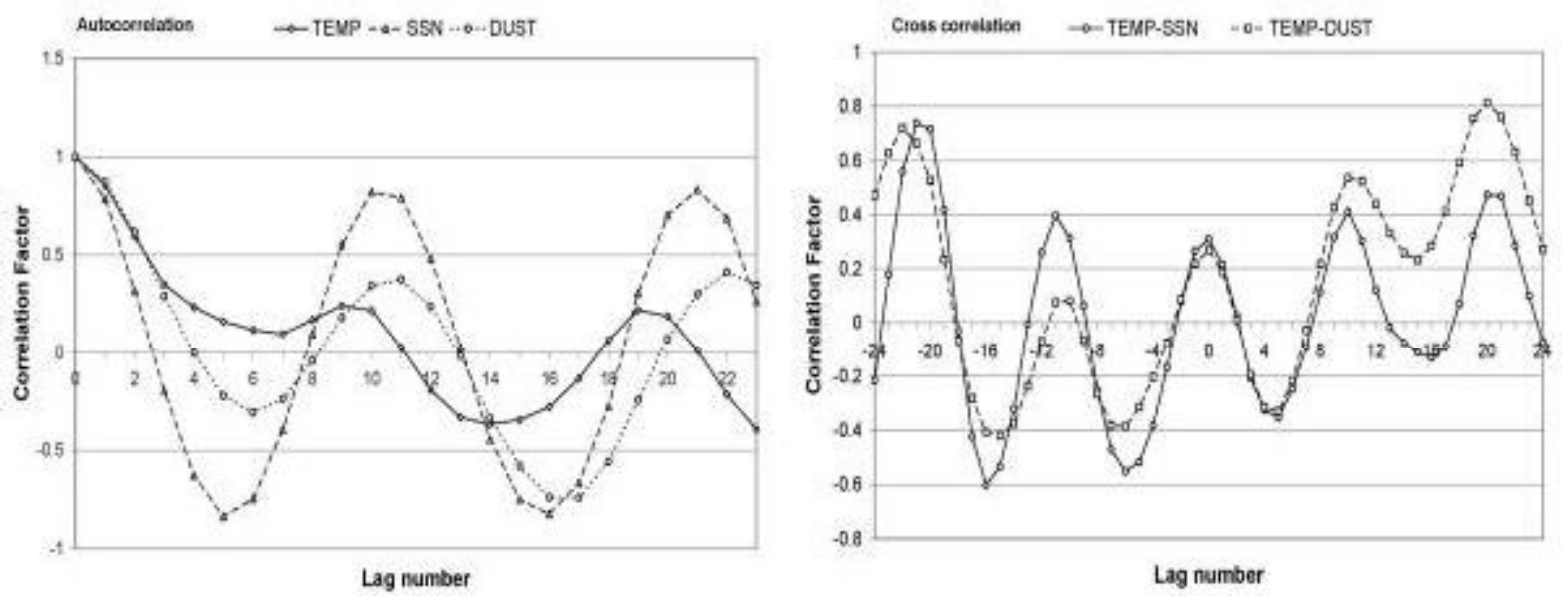

Fig.(7) : Autocorrelation and cross correlation for temperature, dust and sunspot number at Baghdad.
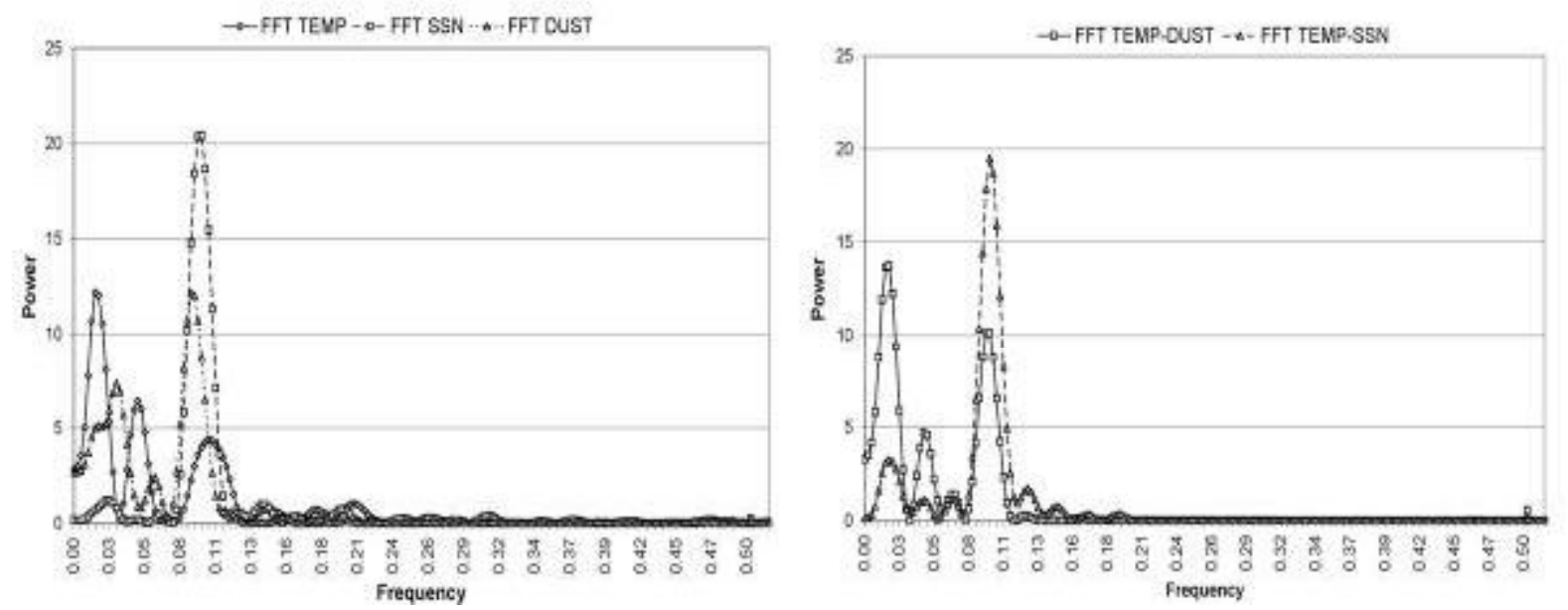

Fig.(8) : FFT spectral analysis for air temperature cycle and cross-correlation with solar and dust cycles at Baghdad.

\section{Discussion}

A thorough look to the distribution of the dust observations for the five stations shows that the dust series vary according to the sunspot cycles. As the southern parts of Iraq are frequently affected by dust storms especially at Nasiriyah and Basrah, it is noted that the data series are highly correlated with the sunspot cycle. Errors occur due to the manual recording of the data and may affect the measured visibility, but not the general tendency of the distribution. The time and spectral confidence tests yield confidence level of $95 \%$ which shows high correlation with the 11 year sunspot cycle taking into 
account the difference in the period of the cycles number 20 (11.66 years), 21(10.25 years), 22 (9.66 years) and 23 ( 11.8 years).

The in-phase, positive correlations between air temperature and the 11-year sunspot cycle, and between air temperature and dust activity indicate the following casualeffect relationship. Higher temperature associated with higher solar activity result drier desert and therefore more dust storm activities in the region closer to the desert. Thus, the results presented in this study provide additional observational evidence of atmospheric response to solar forcing.

\section{Conclusions}

In this paper, we attempt to appraise statistically the significance of the relation between the sunspot cycles and the dust activity for five stations in Iraq. Examination of the data for individual stations using time and spectral analysis shows significant correlation with the sunspot cycles. The potential presence of such relationship has great importance for predication of the dust and dust storms activities across the region. Finally, the appearance of this significant correlation may be due to the stability of the weather conditions in the region especially during periods of summer and winter.

\section{References}

[1] A H Palmer. 1910 The influence of sunspots upon climate, Popular Astronomy $18,8-12$.

[2] HC Willett. 1965. Solar climate relationships in the light of standardized climatic data. Journal of Atmospheric Sciences. 22, 120-137

[3] E J Gerety, J M Wallace,. CS Zerets. 1977 Sunspots geomagnetic indices and the weather: The prognostic value of any connection. Journal of Atmospheric Sciences. 34, 673-678.

[4] D J Hancock, DN Yarger. 1979. Crossspectral analysis of sunspots and monthly mean temperature and precipitation for the contiguous united states. Journal of Atmospheric Sciences. 36, 764-753.

[5] AS. Goudie, Middleton.1992 The change frequency of dust storms through time. Climatic change, 20, 197-225.
[6] W Qian, L. Quan, S Shi. 2002 Variation of the dust storm in China and its climatic control. Journal of Climate, 15, 12161229.

[7] R. Ananthakrishnan, B. Parthasarathy. 2006. Indian rainfall in relation to the sunspot cycle 1871-1978. International Journal of Climatology, 4/2, 149-169.

[8] H. Gleisner, P. Thejll. 2003. Patterns of tropospheric response to solar variability. Geophysical Research Letters, 30, 44-47.

[9] F. Boberg, H. Lundstedt, P. Wintoft P. 2005. 'Influence of solar variability on earth'. European Space Agency report, ESA ITT AO/1-4618/NL/AR.

[10] BA Mohammed. 2009. 'Predication of microwave attenuation due to dust storms over Iraq' to be published.

[11] Solarscience.msfc.nasa.gov.

[12] JC. Davis. 1986. Statistics and Data Analysis in Geology. Wiley. New York.

[13] BA Mohammed. 1994 'Dust storms and weather parameters interaction' Space Research Centre report. Baghdad.

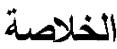

تناول هذا البحث إجراء تحليلات إحسصائية لظــاهرة

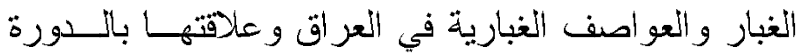
الثمسية للفتــرات بـين (1959-2007) لمحطــة بغــداد و. (1978-2001) لمحطة الرطبة و. (1987-2007) لمحطة بلة بلرة الموصل و الناصرية و البصرة ـ إن الاختبار ات التي أجريت ولاني على البيانات الغبارية لكل محطة تم إخضاعها إلى التحليـل التهل

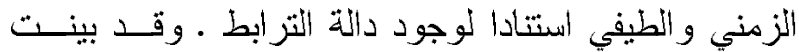
النتائج وجود دورة غباريــة ملحوظــة مسشابهة للــورة الثمسية. فيما بينت تحليلات التر ابط المنقاطع بـين الغبــار و الدورة الثنمسية ودرجة الحرارة وجود نرابط قوبي عند كل

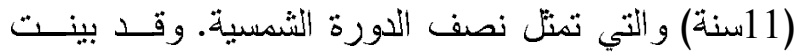

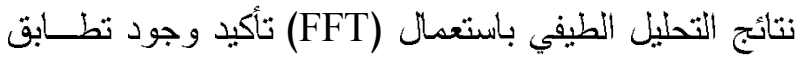
دور ات الغبار مع الدورة الثنمسية. 